Running Head: PETE and social justice education

\title{
How PETE Comes to Matter in the performance of Social Justice Education
}

Alan Ovens, The University of Auckland, a.ovens@ auckland.ac.nz

Sara B. Flory, University of South Florida, sbflory@ usf.edu Sue Sutherland, The Ohio State University, Sutherland.43@osu.edu Rod Philpot, The University of Auckland, r.philpot@ auckland.ac.nz Jennifer L. Walton-Fisette, Kent State University, jfisette @kent.edu Joanne Hill, University of Bedfordshire, joanne.hill@beds.ac.uk Sharon Phillips, Hofstra University, Sharon.r.phillips@ @oftsra.edu Michelle Flemons, University of Bedfordshire, michelle.flemons@beds.ac.uk

Corresponding Author:

Sara Barnard Flory sbflory@usf.edu University of South Florida 4202 E. Fowler Ave.

PED 225

Tampa, FL 33606

(248) 496-9273 


\begin{abstract}
Background: For over four decades there have been calls for physical education (PE) and physical education teacher education (PETE) to address social inequality and foster social justice. Yet, as numerous studies demonstrate, attempts to educate for social justice in PETE are infrequent and rarely comprehensive. This raises the question why it appears to be possible in some situations but not others, and for some students and not others.

Purpose: The purpose of this paper is to examine the multiple socio-political networks or assemblages in which PETE is embedded and explore how these shape the possibilities for students to engage with the concept of social justice and sociocultural issues when learning to teach PE. Two research questions guided this study: How does an orientation for social justice education within education policy affect the standards for enacting PETE programs? How is social justice education encouraged within PETE programs?
\end{abstract}

Methodology: Methodology: Drawing from a broader study of over 70 key personnel in more than 40 PETE programs, we examined how faculty in PETE understand their professional world, identify their subjective meanings of their experiences, and address sociocultural issues (SCI) and social justice education (SJE) within PETE. Data sources included an initial survey, a semistructured interview, and program artifacts. We analyze the ways that SJE/SCI was represented in three national settings (England, the United States, and New Zealand) and identified common themes.

Results: Examination of each national setting reveals ways that SJE and SCI were enabled and constrained across the national, programmatic, and individual level in each of the countries. The coherence of explicit National policy and curricula, PETE program philosophies, and the presence of multiple individual interests in social justice served to reify a sociocultural agenda. Conversely possibilities were nullified by narrow or general National Standards, programs that failed to acknowledge sociocultural interests, and the absence of a critical mass of actors with a socio-critical orientation. These differences in assemblage culminated in variations in curriculum time that served to restrict or enable the breadth, frequency, and consistency of the messages surrounding SCI in PETE

\title{
Conclusion:
}

These findings highlight the importance of acknowledging socio-political networks where PETE operates. The agency of PETEs to enact pedagogies that foreground sociocultural interests is contingent on congruity of the networks. The authors caution that although the 'perfect storm' of conditions have a profound influence of the possibility of transformational learning of SCI in PETE, this arrangement is always temporary, fluid, and subject to changes in any of the three network levels. Additionally, the success of PETE in enabling graduating PE teachers to recognize the inequities that may be reinforced through the 'hidden curriculum' and to problematize the subject area is contingent on the expectations of the schools in which they teach. KEYWORDS: social justice, physical education teacher education, assemblages 
Running Head: PETE and social justice education

\section{Introduction}

As numerous studies demonstrate, educating for social justice remains not only somewhat marginalized in most PETE programs, they also question if it can be enacted effectively at all (for example, Author 2017; Curtner-Smith 2007; Devís-Devís and Sparkes 1999; Evans and Penney, 2008; Hylton, 2015; Mordal-Moen and Green 2012; Standal and Moe 2013). In general, it appears that the ability to enact transformative social justice pedagogies as forms of professional learning are contingent on the particular political, institutional and cultural contexts in which student experience and subjectivity are produced and mediated (Author 2016; Author 2009). In other words, it appears to be possible in some situations but not others, and for some students and not others (Author, 2016). This raises the uncertainty of whether the ability to problematize the field, raise awareness of sociocultural issues and activate a commitment to issues of social justice is the product of the advocacy of particular faculty members, the early socialization of teaching candidates, the pedagogies being used, the expectations and norms of the professional community, or some complex mix of all these factors (and more). In addressing this uncertainty we argue there is a need to better understand the distributed and networked nature of professional learning that extends across and beyond the individual subjectivities of those involved in enacting social justice education in PETE.

What and how students learn about sociocultural issues (SCI) or social justice in physical education within their teacher education has been conceptualized as a product of the curriculum that governs each program. Using curriculum as an analytic concept allows a focus not only on the explicit and intended aspects of what constitutes learning to teach, it also allows consideration of what is learnt covertly and embedded within daily routine and practice; or what 
has been described as being part of a 'hidden curriculum' (Kirk 1992). In other words, what and how students learn about sociocultural and social justice issues is a product of both the explicit and implicit messages relating to knowledge, values, norms and professional dispositions that learners experience in and through their teacher education experience. However, as FernandezBalboa (1993) asserts, the hidden curriculum shapes and mediates not only values, but also experiences and practices. In this way, the hidden curriculum in teacher education can be seen as a disciplinary practice, moving students from the routinized processes of the PETE programme to the confined space of being a professional teacher. Whether students view themselves as docile, dominated actors in school settings, or as advocates willing to challenge and change school practice, the hidden curriculum is connected to what and how they learn through their PETE program.

Recently there have been increasing calls for research on curriculum (and its enactment) to look more broadly at how curriculum emerges from socio-political networks and the flows between key discourse communities and agencies beyond the immediate setting of PETE programs (Evans \& Davies, 2014; Flintoff, Dowling and Fitzgerald, 2015; Penney, 2016; Velija, et al, 2008). For example, Author (2017) points out that when the curriculum policies that govern school physical education have a critical orientation, this can have two key effects on the PETE program. Firstly, the candidates entering PETE may be better able to problematize the subject area and engage with the emancipatory politics that structures the messages around SCI and SJE. Secondly, there is a more coherent professional language between schools and university settings that works to support the development of SCI and SJE knowledge, dispositions and skills. In other words, the professional community are expecting students to be capable of teaching in a 
Running Head: PETE and social justice education

critically oriented way. Certainly, the ability to engage in critical activities and enact

transformative pedagogies in PETE appears connected to the particular political orientations and discursive communities students are situated within (Author, 2016; Mordal-Moen \& Green, 2012; Author, 2009; Author 2016).

This highlights that there is a need to move beyond a critique of the hidden curriculum and look more broadly at the relations and "networks of solidarity" (Ruiz \& Fernandez-Balboa, 2005, 259) that give rise to the curriculum that students experience in PETE. Evans and Davies (2014) argue that if the profession's project is social justice and pursuit of democratic ideals, then there needs to be less of a focus on politics of identity and a greater focus on the relations between PE and new forms of governance that are now prevalent in many countries. In a similar way, Penney (2016) argues that education policy and practice is now conceptualized, discussed, and formulated in many different sites by an increasing number and diversity of actors. Penney and colleagues wrote,

The landscape of both policy and pedagogy can no longer be conceived of as confined to or bounded by the historic governmental structures and relations associated with education systems. The concepts and language of networks, encompassing and extending those structures, are then, fitting as the foundation for contemporary HPE research concerned with contemporary developments in policy, curriculum and pedagogy (Penney, Petrie and Fellows 2015, p. 45)

The aim of this paper is to examine the multiple socio-political networks or assemblages in which PETE is embedded and explore how these shape the possibilities for students to engage with the concept of social justice and SCI when learning to teach physical education (PE). While 
framed within an examination of curriculum, our focus goes beyond a focus on curriculum texts to conceptualize curriculum as a performative process that connects and encompasses policy and pedagogy (Penney 2016). As Penney suggests, such a process is “inherently complex, associated with many sites, and that implicate many people in the pursuit of various interests in and for PE curriculum" (Penney 2016, 131). Such an approach resists viewing curriculum processes in linear and hierarchical ways, preferring instead to frame curriculum within an ecological perspective as complex socio-political formations that influence curriculum practice in preservice teacher education. In so doing, we aim to shift away from constructions of the participants in such configurations (such as academic faculty, the professional teaching community, accreditation committees, student teachers, etc.) as autonomous actors and instead build a more complex, nuanced and layered understanding of the multidimensional influences that work together to shape what is performed as PETE in any particular context.

\section{PETE as Socio-Political Assemblage}

Viewing teacher education as emerging from a broad constellation of factors in play at a particular moment problematizes the notion that there is a universal concept called 'teacher education' and that teaching about SCI is largely a pedagogical concern which is best approached by research orientated towards psycho-social explanations and strategies (Green, 2006). Instead, this essentialist view is replaced with the notion that what is identified as social justice and 'PETE' is interdependent, decentered, and grounded in the particulars of history, place, and people. From this perspective whatever practices are enacted around educating students on SCI are seen as being enabled by a system of social relations and differentiations constituted by multiple, interpenetrating and layered systems (Alhadeff-Jones 2012). The 
Running Head: PETE and social justice education

following dynamic elements are central to understanding the emergent and performative nature of curriculum practices in PETE that help frame the approach we are using.

First, PETE happens relationally in and through the interactions, intra-actions and effects of socio-political networks of power. This implies that while there is an 'actuality' about PETE, inasmuch as it can be actualized in policies, texts, and practices, there is nothing essential or substantial to its nature. There are only entanglements of actors and subsequent performances and affects. In this sense, PETE is a process that continuously emerges, morphs, and evolves. It is fluid, dynamic, and highly contingent on its constituent elements. This is not meant to imply that there are not periods of stability in a program and its curriculum, but that such stability can be mistaken for an objectivity in which key elements, like curriculum, are transferred into being a 'thing' rather than viewed as an emergent process. In the frame of relationality, there are no pre-existing beings to be 'known.'

Secondly, PETE emerges from a particular formation or collective of constituent elements. While there are a broad range of labels used to describe such collective entities, in this paper we draw on the concept of assemblage as a useful way of thinking about the multiplistic, co-constituted nature of PETE. An assemblage is a diverse collective of elements, both material and non-material, that come into composition in different ways at different times to produce something, such as a program, curriculum or particular orientation to teaching (Strom 2015). As such, PETE can be viewed as an assemblage composed of people, classroom spaces, texts, technology, as well as disciplinary forces whose power and agency are elicited through various routines (e.g., lessons, weekly timetables), regulations (e.g., institutional and program policy, graduating standards), and discourse communities (how knowledge is ordered in disciplinary 
Running Head: PETE and social justice education

fields and subject areas) (deFreitas 2012). Framed in this way, SCI within PETE is not a product enacted by autonomous actors, but co-produced through the collective action of interconnected elements. Each element that composes the SCI assemblage is not held as separate, discrete, and neutral, but is conceived as an active agent in the joint production of the practices that are constructed.

Closely related to this point is the third dynamic that PETE is not a closed system, but emerges through both its external connection(s) and function(s), and from its internal relations. In other words, PETE has no coherent essence solely defined by the organic functioning of some internal logic, but from broad assemblages operating in the tertiary sector, such as accreditation boards, institutional policies, professional communities, and political ideologies. Penney (2016) demonstrates this by drawing on the work of Bernstein to show how different recontextualizing fields become networked in the process of governing pedagogic ideas in the PE curriculum. This implies that PETE is not some standardized entity, but rather, a component part of a unique, circumstantially bound, and un-reproducible assemblage that also links with developments in schooling, the nature of the PE field, and conceptions of professional teacher. As such, PETE and its associated practices, is fluid and never completed (McKay, Carrington, and Iyer 2014).

Finally, emergence is normatively governed. This is an important point since it could be assumed from the points above that anything is possible since everything seems to emerge from the collective action of distributed actors. In other words, anything could emerge as PETE because anything is permissible. However, this is clearly not the case. What is missing is consideration of the cultural-discursive, socio-political and material-economic dimensions that serve to govern the particular program or orientation that emerges. Kemmis and Grootenboer 
(2008) describe such dimensions as 'practice architectures' that, “... prefigure practices, enabling and constraining particular kinds of sayings, doings and relatings among people within them, and in relation to others outside them" (p. 59). Framed in this way, the contexts of PETE are not only the material architectural arrangements that enable and constrain the performance of SCI, but also structure the discursive and relational conditions that shape how SCI becomes enacted within the program curriculum and pedagogy (Edwards- Groves et al. 2010).

It is worthwhile pausing here a moment to highlight the role of enablers and constraints in normative governance. Davis and Sumara (2006) suggest that the notion of enablers and constraints are essentially one-in-the-same since they both "refer to the structural conditions that help to determine the balance between sources of coherence that allow a collective to maintain a focus of purpose/identity and sources of disruption and randomness that compel the collective to constantly adjust and adapt" (p. 145). In this way, enablers and constraints are not prescriptive in the sense that they dictate what must be done, rather they are expansive, indicating what might happen (Davis, Sumara and Luce-Kapler 2008). In other words, both enablers and constraints draw attention to the dynamic balance between "sufficient organization to orient agents' actions and sufficient randomness to allow for varied and flexible response" (Davis and Sumara 2006, 149). Enablers and constraints become useful tools for conceptualizing how the self-organizing actions of agents are shaped by contextual features (whether those agents are individual faculty working within university systems or PETE programs working within teacher accreditation systems) and how the limitations in complex context fuel expansive responses.

Given the elements outlined above, the purpose of this paper is to examine the multiple socio-political networks or assemblages in which PETE is embedded and explore how these 
Running Head: PETE and social justice education

shape the possibilities for students to engage with the concept of social justice and sociocultural issues when learning to teach PE. Two research questions guided this study: How does an orientation for social justice education within education policy affect the standards for PETE programs? How is social justice education encouraged within PETE programs?

\section{Methods}

We drew the data from a broader qualitative study conducted from fall 2015 through fall 2016. This broader study set out to examine how faculty in PETE understand their professional world, identify their subjective meanings of their experiences, and address SCI and SJE issues within PETE that marginalized individuals based on issues of power, social justice, and oppression (Creswell, 2014).

\section{Setting and Participants}

Over 70 PETE faculty from more than 48 PETE programs across Australia (AUS), Canada, England, Ireland, New Zealand (NZ), Sweden and the United States (US) participated in this study. Purposive sampling (Miles and Huberman 1994) was utilized to recruit participants who identified as a physical education and/or health education faculty member in a teacher preparation program. Participants did not need content knowledge of, or experience with, sociocultural issues to become a participant. Participants were recruited by personal contact made by the researchers, and at state, national, and international conferences. Participants had a wide range of professional experiences, which included the length of time in the profession (ranged from one to over 30 years), the type of institution employed (e.g., teaching/researchbased, small vs. large institutions), educational backgrounds (all had a terminal degree) and courses taught. Permission to conduct the study was obtained through each of the authors' 
Running Head: PETE and social justice education

university Institutional Review Board/Ethics Committee and informed consent was granted prior to the start of the study. Informed consent assured participants anonymity, as pseudonyms were utilized for the names of participants and their respective institutions.

\section{Data Sources}

Data were collected through an informational survey and one-on-one semi-structured interviews. A pilot study was conducted with 15 participants in 2015. Based on the data gathered from the pilot, the informational survey was developed and the interview guide revised. The remainder of the research study was conducted in 2016. All data were collected by the researchers and uploaded to a private research project in Dropbox.

Informational survey. The informational survey was sent to each participant to provide context and background knowledge about themselves, including their geographic living experiences, educational degrees obtained, professional positions held in higher education, and a social identity profile. The informational survey was completed electronically in a word document and sent via email to the researcher.

Interviews. Participants took part in semi-structured interviews between 30 and 90 minutes long. Interviews followed an interview guide, with further probing questions added when necessary. Questions for the interviews focused on participants' educational background; beliefs, understanding and perspectives about social justice and sociocultural issues; and pedagogy within PETE programs and courses related to social justice and sociocultural issues. The interviews occurred in person (e.g., at their office, at a conference), via SKYPE, or over the phone. All interviews were audio-recorded.

\section{Data Analysis}


Running Head: PETE and social justice education

The resulting data set provided a very broad and rich snapshot of contemporary PETE programs. For example, the interview data alone stretched to over 1000 pages. The complexities involved in the analysis of how SJE and SCI are enabled within heterarchical assemblages present both interpretive and representational challenges. The interpretive challenges included the difficulties and appropriateness of analyzing such a large data set. We addressed this by focusing our analysis on the data collected from three national settings: England $(\mathbf{n}=\mathbf{2 0})$, the US $(\mathbf{n = 3 6})$ and New Zealand (n=9). We chose national settings principally because the educational "system" of each is governed by the policies and funding provided nationally within each country. While we acknowledge there are differences within each system, we sensed that the differences between countries could provide a valuable contrast to help illustrate how SCI is addressed in and through PETE/PESP. The choice of countries was also facilitated by the quantity of data we had pertaining to each country, and the familiarity the researchers had of each context to enrich the analysis. The key representational challenge was to find a way to report the findings within the word limit set by the special edition. We decided to not represent each national context as a case study, but instead see them as providing a form of vertical axis to differentiate context and allow the data to be presented as a form of horizontal themes that could be discussed.

Initial data analysis occurred using content analysis and the constant comparative method (Corbin and Strauss 2008). Each researcher analyzed the data from a specific country using open coding, or line-by-line analysis, to develop initial codes. Each researcher then conducted axial coding, which included collapsing the initial codes into primary themes and then providing descriptions for each theme (Corbin and Strauss 2008). 
Running Head: PETE and social justice education

Trustworthiness of this research study was ensured by utilizing multiple sources of data, engaging in conversations and discourse among the researchers that challenged and questioned one another's perspectives and interpretations, recording in our researcher journals, and maintaining an audit trail. Inevitably though, we acknowledge that our data set is incomplete and partial, mediated by the inconsistencies of narrating personal experiences through interview, the inflation of affect in written course artifacts, and perspective provided by data source. We recognize that the voices of students, teachers, administrators, researchers, and politicians who co-participate in PETE assemblages are missing and may have been able to provide counter-narratives or alternative ways of reading our data. However, given that all inquiry is partial, ambiguous and tentative (Kincheloe and Berry 2004), we collated a data set that not only resonates with the "messiness" of enacting curriculum in actual settings, but also provides a set of empirical materials that were generative for making curriculum practices available for analysis and reflection.

\section{Findings}

From the outset it was very clear that we had to be careful when talking about physical education teacher education and assume we were all meaning the same thing. As noted by Zeichner (2014), there is an increasing diversity of pathways for becoming a teacher, and each prefigures the "sayings, doings and relatings" (Author) of learning to teach in very different ways. This was important to remember because at the surface level, the structure of teacher education in each country looked very similar. For example, all three countries had two main pathways into teaching. The first was a 4-year undergraduate PETE programme leading to Qualified Teacher Status. The second was 3-Year PESP undergraduate degree plus 1 year 
Running Head: PETE and social justice education

postgraduate PETE programme to Qualified Teacher Status. However, below this basic structure there were significant differences in both content and emphasis between countries. For example, within the US system, between $30-40 \%$ of an undergraduate degree is devoted to general education courses resulting in no more than two and a half years of courses in physical education teacher education. By contrast, in the New Zealand system almost $80 \%$ of the degree is devoted to physical education teacher education.

The following three themes present how SJE and SCI were enabled and constrained across the national, programmatic, and individual level. Explicit national policy and curricula, PETE program philosophies, and the presence of multiple individual interests in social justice provided enabling conditions. Narrow or general National Standards, programs that failed to acknowledge sociocultural interests, and the absence of a critical mass of actors with a sociocritical orientation constrained the possibilities of SJE and SCI.

\section{Normative governance and impact of national context}

Within each national setting Teacher Education was governed rather than determined. In other words, rather than specifying how teacher education should be conducted, each country used a range of mechanisms, such as standards, national curricula and accreditation boards, to control the institutional nature of teacher education programmes. Each country specified standards guiding the preparation of pre-service teachers were deemed to encourage or limit space for possibilities in addressing SCI in and through PETE/PESP. These standards were created at the Governmental level in England (Department of Education) and at a national level in New Zealand (Education Council) and the US (Council for the Accreditation of Educator 
Preparation, and more specifically through the Society of Health and Physical Education, which is the Specialized Professional Association for physical education). In addition, another mechanism in both England and New Zealand was the presence of a National Curriculum for Physical Education. The presence of the National Curriculum normalizes or validates particular messages (such as acceptable curricular content), influences the professional community relative to expectations for teacher education, and influences the students entering programs in what they consider to be 'physical education'.

The use of standards as a governing mechanism for PETE curriculum practice in each national setting encouraged the inclusion of SCI within PETE/PESP programs. The level of specificity in the language within the standards and how programs interpreted or adhered to these standards varied across countries and programs. Within some national contexts, there was a very explicit link between how these teaching standards were addressed within programs. In New Zealand, the Graduating Teacher Standards are quite specific and intended to provide clear expectations of what new teachers are capable of doing. They are also connected to a deeper ethos of what quality teaching involves in the New Zealand setting as well as providing some flexibility in how they are interpreted within programs.

The Teacher's Standards in England, which are used in determining the minimum level of practice and to assess students pursuing Qualified Teacher Status (Department of Education 2011), includes specific language that addresses sociocultural knowledge and/or competency, which guided how PETE/PESP programs prepared their pre-service teachers. This framework facilitated the inclusion of SCI within one PETE program because, "we have to cover the teacher's standards, it's absolutely embedded in the standards that you have to go down that 
Running Head: PETE and social justice education

route" (Sophie, England). While the Teacher's Standards language is specific, it was less clear how elements of SCI or SJE were embedded into Sophie's particular PETE program.

The Initial Physical Education Teacher Education Standards (US) state that students should demonstrate professional responsibility and culturally competent practices (Standard 6) and meet the needs of diverse needs of all students in planning and implementation (Standard 3). This explicit language placed a responsibility on teacher educators to address issues of cultural competence and diverse student needs in teaching. A number of participants referred to these standards as a facilitator in addressing SCI within their programs.

Contrary to the facilitative nature of the standards regarding addressing SCI within PETE/PESP programs, the lack of specificity of the language or the inclusion of only a few sociocultural groups within the language acted as a limiting factor for some programs or contexts. Although the recently revised standards for Initial Physical Education Teacher Education (SHAPE America - Society for Health and Physical Educators 2017) uses explicit language to promote cultural competence in teachers, the previously published standards (National Association for Sport and Physical Education 2008) suggested that teachers communicate in ways that conveyed respect and sensitivity to students (Standard 6.4). This very general language may limit preparing teachers that can address sociocultural issues and issues of social justice in their teaching as it does not specifically address cultural competence or sensitivity. In addition, the use of the term "diverse needs of all students", which is present in both the 2008 and 2017 standards, was often referred to by participants in the context of [dis]ability. This was addressed by many PETE programs through taking an adapted physical education class rather than considering the breadth of diverse needs of all students in physical 
Running Head: PETE and social justice education

education. Similarly, language in the Teacher's Standards addressed some specific sociocultural issues such as special educational needs, English as an additional language and [dis]ability, but failed to address other specific SCI.

Some participants also viewed the Teacher's Standards framework as a limiting the space for possibilities as it was operationalized as a, "tick-box exercise" relative to social justice issues and 'they're getting ticked off 'the students can do this'. Well, I do believe if you really spoke to those students, they wouldn't have the first clue about what it actually was" (Brad, England). Gary (England) also agreed with this point indicating that, "we talk about teacher preparation, teacher education, and we need to educate teachers better. But more and more, it's becoming about, being a mechanic. Pass this, pass this, pass this, right you're qualified to teach"

\section{Programs as regulatory structures enabling social justice education}

Programs are a key organisational hub in which PETE emerges at the nexus of national, institutional, and disciplinary forces. Programs are the existential architecture in which PETE becomes expressed as courses and pedagogical spaces (classrooms, gymnasia, practica) (Author). It is a space in which the key orienting principles guiding the program are expressed as mission statements and underpinning philosophies. We observed considerable difference in the programs we analysed in how they addressed SCI and SJE. This was most obvious in aspects like student recruitment and selection, course and curriculum development, staff (faculty) recruitment and instructional strategies employed. These factors work in ways to enable and limit the possibility for addressing SCI and SJE within PETE/PESP programs. Perhaps more 
Running Head: PETE and social justice education

importantly, we noted that a lack of alignment between these factors however, works to restrict or conflate the space to effectively facilitate addressing SCI in programs.

An explicit program mission or philosophy that supported including SCI within PETE/PESP programs created a space for possibilities within all three countries. A good example of this alignment occurred in one PETE program within New Zealand where that the program philosophy stated that, "It conceptualizes Physical Education within a socially-critical perspective where the work of the professional physical educator is related to the wider social and world scene and concerned with how Physical Education makes a 'better world"” (Accreditation documentation, 2005). This was then aligned with the guiding principles of the program that, for example, stated that physical education, as a site of cultural practice, needs to be practiced within "a reconstructed understanding of the projects of human empowerment and emancipation in and through physical culture" (Accreditation document 2005, 25).

Further alignment between program mission or philosophy and programmatic structure clearly created the space for educating about SCI. The majority of programs that we analysed that addressed SCI embedded SCI within a range of courses or modules, with some also adding a stand alone course addressing SCI within physical education. A programmatic structure like this created a spiraling form of curriculum that enabled multiple opportunities for students to engage with SCI. This broad strategy for SJE was reflected in Ivan's (New Zealand) comment when explained the logic behind how their program had been designed.

I think particularly in years three and four of the program there is a strong move to a criticality, to looking at social justice issues, inequalities and power relations. I am not convinced that in year one and two that we do that particularly strongly there but I think as 
Running Head: PETE and social justice education

they come through by the end of the fourth year I would say our fourth year students have got a good understanding of those issues.

Timothy (England) reiterated the importance of building on experiences throughout a program that enable students to situate the knowledge gained earlier in the PETE program to physical education settings,

So they look at how those [SCI] issues [taught] at Level 4 might be contextualized in a PE environment and what would it look like for somebody who is disengaged in PE because of their social background or whatever it is, and then how would a teacher's pedagogy reflect that and change to engage those individuals.

Nicholas (England) indicated that his program had, "a clearly defined pathway with the course which is physical education teacher education...core modules that are associated with sociology and appreciating social justice and social inequality" and also had "issues associated with diversity and equity and equality are embedded as part of the taught core element."

In contrast, we observed that a major factor limiting the effective inclusion of SCI within PETE/PESP was most often identified by participants as curricular time and program structure. Calvin (US) indicated that his students only received 21 credit hours of instruction within physical education, and the rest was handled by the College of Education. Eric (US) shared, "In the priority of things, I need to make them a good teacher first...just the basic skills of teaching. If we don't have those, I feel like the other pieces might get lost. So, we're going to make sure we get the content." Katie (England) indicated that her main constraint was "time and trying to fit everything in... and I'm sure that is a common issue". However, this limiting factor was also tempered with the recognition that more time may not be realistic. Marilyn (England) stated, "So 
if I could buy another year on the program that would be something, but that's not realistic, that's out of my control in that sense."

Some participants indicated that faculty and their collective sense of the key issues in the field shaped curriculum priorities. Ed (England) felt that his program "has become a reflection of research, research interests... [of] some of our more recent appointments, so it looks like we are specializing in physical activity", and went on to say "that's fine if that's what we want to do, but it doesn't interest me so I just have to accept that." External forces such as the push for employability upon completion of a degree was also highlighted as limiting in relation to incompatibility with program mission or philosophy and structure. Timothy (England) reflected that, "we're being driven to create programs that meet the needs of a variety of employers" and that students understanding of SCI is not one of those current needs.

For programs where an infused or embedded approach to addressing SCI was employed, participants expressed that they were unsure it was enough to fully prepare students. Tom (US) shared:

It can be very siloed; it isn't something that is always pervasive across the program and discussed in a larger way. And we try to have conversations and I think it's a little informal, and I think that it could become a little more formalized. I want my students to know that sociocultural issues influence who the kids are and who they are in your class on that day. And you need to approach them in specific ways based on who they are and what their background is....but it needs to be integrated program-wide.... I think as a profession, we need to get more on board with this - as part of the content of 'what we do.' 
Marilyn (England) indicated that in her program, “on the one hand we're flagging or highlighting things that are important, but we're not really following through on how to help people to actually survive or work within those spaces."

\section{The importance of the collective over the individual}

An observed difference between the programs we analysed was the constitution of their faculty (teaching staff). A critical mass of key personnel or actors with a socio-critical orientation, research expertise, and a belief or passion in addressing SCI was identified as influential in encouraging both program design oriented to SJE and enacting forms of curricula that would enable meaningful engagement for students. On the contrary, these factors were also highlighted as limiting in programs where they were not present.

A significant number of key personnel relative to research interests and expertise was highlighted as an important factor for participants from all three countries. Having a number of people with a clear commitment to, and understanding of, SCI or a socially critical orientation was seen as essential in creating space for addressing SCI. In particular, Ivan (New Zealand) stated that,

But I think there are some key teachers in the program who do that [SCI] really, really well and I think the key teachers are Joan, who does a lot of social justice issues through getting the students to engage in community work or community liaise with community, service learning as she would call it, looking at social justice issues in that regard. Sarah does that a lot with her critical pedagogy and I do a lot of it through social critical understandings of PE as well. 
Running Head: PETE and social justice education

Nicholas (England) shared that within his program there are individuals who are experts in the different areas of SCI and, "are very experienced in delivering and educational package to our students to help them understand how important appreciating difference and social justice might be within teacher education." Sarah (New Zealand) acknowledged the importance of the people involved in her PETE program because the university context can be quite constraining. As she comments,

So in terms of me personally, I try to be a critical pedagogue but it's really difficult within a university context because there are real tensions there, which you would understand in terms of having learning outcomes and assessments and measuring accountability and ranking and all those sorts of things. However, within that, I guess do my best to try and get students to understand the nature of power relationships in classes and how that impacts on students and how students feel in classes.

Support for SCI from colleagues and senior management was acknowledged as an important by some participants but this ranged from being left alone to deliver what was felt to be essential, to collaborating or supporting efforts to intentionally address SCI. Sophia (England) relayed that, "we can put whatever we want into our programs, you know there's not someone saying, oh you can't do that." Timothy (England) felt supported in his efforts to address SCI in his program through the opportunity to team teach a seminar as it allows him to, "model the type of debate that we wanted students to begin to engage with."

Within England and the US, participants in programs that did not possess a critical mass of key personnel with a strong belief in addressing SCI faced limitations an individual level. Jeff (England) indicated that he would want "more staff being confident in addressing social justice 
concerns, not as its own thing, but perhaps weaving it into their teaching", so that it was not just him and one other person tackling SCI in his program. Nathan (England) explained that the ideal situation would be, "for a team that works at the same level I suppose, and everybody had similar beliefs, similar ideas, knowledge even, you know... so much more could be done. Far more flexible situations than maybe there are at the moment".

Some participants highlighted a lack of knowledge or expertise in how to include SCI within PETE/PESP programs as a strong limitation. Pat (US) stated that she was, "A little uncomfortable [teaching about SCI] as I didn't have a background in it...I am more the logistics, anal, scientific side of it. So that's presented a little challenge". Karen (England) felt that she has personally limited her space for possibilities in addressing SCI in her program,

I felt uncomfortable delivering some of the material, as I say some of the material that I can't relate to. So, for example, delivering stuff on sexuality, which I kind of have no experience of... and maybe imposed restraints on myself in the kind of language that I would use.

Despite being part of the national standards for initial teacher preparation, some participants could not identify any place within their US PETE programs where sociocultural issues and social justice were addressed. In addition, some of these participants did not feel qualified to discuss sociocultural topics or issues of social justice. One of these participants shared that he felt that only someone with a doctorate in specific issues related to social justice in physical education should teach about SCI in PETE programs. A more common approach to addressing SCI in US PETE programs was through courses taken outside of the physical education program. Larry (US) shared, "at a research institution like mine, we have the resources to cover some 
Running Head: PETE and social justice education

content knowledge, pedagogical content knowledge, and general pedagogy. They get all of their diversity instruction through the College of Education."

\section{Discussion}

Our purpose in this paper was to open a dialogue intended to re-think curriculum practice in PETE with a focus on questioning how SJE and SCI are enabled within a broad assemblage of actors and agencies that govern the performance of PETE. We acknowledge that it is a goal that many are undertaking at the moment as attention swings towards understanding the restructuring of education discourse within an ecological perspective as complex sociopolitical formations that influence curriculum practice in preservice teacher education (Evans \& Davies, 2014; Penney, 2016, Velija, et al., 2008). In other words, the emphasis is less about studying the content of the hidden curriculum and more about discovering and understanding the networks or the policy regimes producing the hidden curriculum. This involves less of a focus on relations within institutions that construct SCI and SJE as forms of identity politics (Evans \& Davies 2014) or as pedagogies for critical theory (Author 2017), but more on relations between a broader array of actors, agencies, discourses, and social events that displaces students into a particular political project. In other words, our focus was not on student subjectivity, but on student subjectivation (Author, 2017).

With respect to this paper, and in acknowledging the positionality and perspective provided by the data set, we focused specifically on understanding curriculum as enablers and constraints that compel the activities of participants to constantly adjust and adapt. The findings lend support to the proposition that many of the curricular and pedagogical practices apparent in PETE cannot be studied in isolation but have to be considered as part of a broader pattern of 
Running Head: PETE and social justice education

performing within cultural-discursive, socio-political and material-economic dimensions that serve to govern the particular program or orientation that emerges. The implication here is that that individual agency to enact a particular pedagogy should not be considered in isolation, or as one-off tactical responses, but instead seen in relation to the assemblages and networks that validate it as meaningful PETE practice. In other words, participants reported greater confidence in their ability to affect SJE and address SCI when there was a broader and coherent network of courses, messages, practices, policies and content to validate SJE and SCI as core knowledge within the field of physical education pedagogy.

Linked to this, the findings also suggest that PETE programs with a strong SCI focus have more alignment among a cluster of factors at all three levels - national, programmatic, and individual - which combine to send multi-tiered, consistent messages to students regarding SCI. Teaching for SCI in PETE programs seems most encouraged when they are supported by and align with structures in place at the national level, such as national standards, curriculum materials, or other policy documents. Momentum for SCI is further enabled when this is coupled with PETE personnel and school teachers who passionately encourage and enact pedagogies that provide experiences that promote understanding about topics related to social justice. Penney (2016) alluded to the importance of broader discourse communities. In essence, it is not just the individual people teaching in PETE programs that make them successful or unsuccessful. Rather, having a critical mass of individuals that believe in SCI and SJE that are supported at the programmatic level (Ruiz \& Fernandez-Balboa 2005), and further supported by national policies or documents provide the most ideal circumstances for enacting a comprehensive curriculum (Author, 2016) and a professional teaching community that expect graduates to have such 
professional knowledge. This "perfect storm" of conditions is not the only way to enact an effective transformative pedagogy in professional learning, but as Author (2009) suggested, political and cultural conditions have profound influence.

In conclusion, what we have highlighted is the importance of acknowledging the sociopolitical networks involved in the performance of PETE. This is important because the focus for enacting SJE has often been on the pedagogical tactics and methods used within individual courses and their impact on student subjectivity. As we have argued, the agency of PETEs to enact pedagogies that foreground sociocultural interests is enabled and constrained by a range of factors operating in the hierarchy of curriculum practice. Advocacy for Social Justice Education needs to go beyond a focus on pedagogy and include strategies for using standards and curriculum policies at the macro level to influence the balance, selection and inclusion of courses and faculty personnel as well. Curriculum practice is always dynamic and subject to changes in any of the three network levels, so advocacy to achieve the 'perfect storm' of conditions needs to be seen as an ongoing and important political struggle. While the easy battle may be to affect pedagogical change within the PETE lesson, the success of PETE in enabling graduating PE teachers to recognize the inequities that may be reinforced through the 'hidden curriculum' and to problematize the subject area is ultimately contingent on the assemblages that normalise SJE and SCI as a legitimate aspect of curriculum practice in PETE. 
Running Head: PETE and social justice education

\section{References}

Alhadeff-Jones, M. 2012. Transformative Learning and the Challenges of Complexity. In Handbook of Transformative Learning: Theory, Research and Practice, edited by T.P. Cranton and Associates, 178-194. San Francisco: Jossey-Bass

Curtner-Smith, M. D. 2007. The Impact of a Critically Oriented Physical Education Teacher Education Course on Preservice Classroom Teachers. Journal of Teaching in Physical Education, 26(1): 35-56.

Davis, B., and D.J. Sumara. 2006. Complexity and Education: Inquiries into Learning, Teaching, and Research. Mahwah, NJ : Lawrence Erlbaum Associates.

Davis, B., D. Sumara, and R. Luce-Kapler. 2008. Engaging Minds: Changing Teaching in Complex Times (2nd end). New York: Routledge.

deFreitas, E. 2012. Classroom as rhizome: New strategies for diagramming knotted interactions. Qualitative Inquiry, 18(7), 557-570.

DevÌs-Devİs, J., and A.C. Sparkes. 1999. Burning the Book: A Biographical Study of a Pedagogically Inspired Identity Crisis in Physical Education. European Physical Education Review, 5(2): 135-152.

Edwards- Groves, C., R. Brennan Kemmis, I. Hardy, and P. Ponte. 2010. Relational Architectures: Recovering solidarity and Agency as Living Practices in Education. Pedagogy, Culture \& Society, 18(1): 43-54.

Evans, J., and B. Davies. 2014. Physical Education PLC: neoliberalism, curriculum and governance. New directions for PESP research, Sport, Education and Society, 19(7): 869-884, DOI: 10.1080/13573322.2013.850072

Evans, J. and Penney, D. 2008. Levels on the playing field: The social construction of physical 'ability'in the physical education curriculum. Physical Education and Sport Pedagogy, 13(1): 31-47.

Fernandez-Balboa, J.M. 1993. Sociocultural characteristics of the hidden curriculum in physical education. Quest, 45(2), 230-254.

Fitzclarence, L., and R. Tinning. 1990. Challenging hegemonic physical education: Contextualizing physical education as an examinable subject. In Physical education, curriculum and culture: Critical issues in the contemporary crisis, edited by D. Kirk and R. Tinning, 169-193. London: Falmer Press

Flintoff, A., Dowling, F. and Fitzgerald, H. 2015. Working through whiteness, race and (anti) 
Running Head: PETE and social justice education

racism in physical education teacher education. Physical Education and Sport Pedagogy, 20(5): 559-570.

Gerdin, G., R. Philpot and W. Smith. 2016. It is only an intervention, but it can sow very fertile seeds: graduate physical education teachers' interpretations of critical pedagogy. Sport, Education and Society: 1-13.

Hylton, K. 2015. 'Race' talk! Tensions and contradictions in sport and PE. Physical Education and Sport Pedagogy, 20(5): 503-516.

Kemmis, S., and P. Grootenboer. 2008. Situating praxis in practice: Practice architectures and the cultural, social and material conditions for practice. In Enabling praxis: Challenges for education, edited by S. Kemmis and T. Smith, 37-62. Amsterdam: Sense Publishers.

Green, K. 2006. Physical Education and Figurational Sociology: An Appreciation of the Work of Eric Dunning. Sport in Society 9(4): 650-64.

Kincheloe, J., and K. Berry. 2004. Rigour and Complexity in Educational Research. London: Open University Press.

Kirk, D. 1992. Physical education, discourse, and ideology: Bringing the hidden curriculum into view. Quest, 44(1): 35-56.

McKay, L. M., S. Carrington, and R. Iyer. 2014. Becoming an inclusive educator: Applying Deleuze \& Guattari to teacher education. Australian Journal of Teacher Education, 39(3): 178-196

Mordal-Moen , K., and K. Green. 2012. Neither shaking nor stirring: A case study of reflexivity in Norwegian physical education teacher education. Sport, Education and Society, 19 (4): 415-434.

Ovens, A. 2016. Trasformative aspirations and realities in Physical Education teacher education. In C. Ennis, (Ed.) Routledge Handbook of Physical Education Pedagogies, (Chapter 19, pp. 295-306). New York: Taylor and Francis.

Ovens, A. 2017. Putting complexity to work to think differently about transformative pedagogies in teacher education. Issues in Teacher Education.

Ovens, A., and R. Tinning. 2009. Reflection as situated practice: A memory-work study of lived experience in teacher education. Teaching and Teacher Education, 25(8): 1125-1131.

Penney, D. 2016. Policy and possibilities. In C. Ennis, (Ed), Routledge Handbook of Physical Education pedagogies, (Chapter 9, pp. 131-142). New York: Taylor and Francis. 
Running Head: PETE and social justice education

Penney, D., K. Petrie, and S. Fellows. 2015. HPE in Aotearoa New Zealand: the reconfiguration of policy and pedagogic relations and privatisation of curriculum and pedagogy, Sport, Education and Society, 20:1: 42-56, DOI: 10.1080/13573322.2014.947566

Philpot, R. 2016. Shaking students' cages: A Freirean pedagogy that challenged PETE students' beliefs about physical education. International Journal of Critical Pedagogy, 7(1): 143164.

Ruiz, B. M., and J.M. Fernández-Balboa. 2005. Physical education teacher educators' personal perspectives regarding their practice of critical pedagogy. Journal of Teaching in Physical Education, 24(3): 243-264.

Standal, Ø. F., and V.F. Moe. 2013. Reflective practice in physical education and physical education teacher education: A review of the literature since 1995. Quest, 65(2): 220-240.

Strom, K. 2015. Teaching as assemblage: Negotiating practice in the first year of teaching. Journal of Teacher Education, 66(4): 321-333.

Velija, P., S. Capel, W. Katene, and S. Hayes. 2008. Does knowing stuff like PSHE and citizenship make me a better teacher?': Student teachers in the teacher training figuration. European Physical Education Review, 14(3): 389-406. 